C2008 IEEE. Personal use of this material is permitted. However, permission to reprint/republish this material for advertising or promotional purposes or for creating new collective works for resale or redistribution to servers or lists, or to reuse any copyrighted component of this work in other works must be obtained from the IEEE. 


\title{
Genetically Optimized Fuzzy Placement and Sizing of Capacitor Banks in Distorted Distribution Networks
}

\author{
Marjan Ladjavardi, Student Member, IEEE, and Mohammad A. S. Masoum, Senior Member, IEEE
}

\begin{abstract}
A genetic algorithm (GA), in conjunction with fuzzy logic (FL) (approximate reasoning), is proposed for simultaneous improvement of power quality (PQ) and optimal placement and sizing of fixed capacitor banks in distribution networks with nonlinear loads imposing voltage and current harmonics. Economic cost is defined as the objective function and includes the cost of power losses, energy losses, and that of the capacitor banks while the voltage limits, number/size of installed capacitors at each bus, and the PQ limits of harmonic standard IEEE-519 are considered constraints. Fuzzy approximate reasoning is used to calculate the fitness function in order to consider the uncertainty of decision making based on the suitability of constraints $\left(S_{T H D}, S_{V}\right)$ and the objective function (cost index) for each chromosome. Simulation results for the 18-bus and 123-bus IEEE distorted networks using the proposed GA-FL approach are presented and compared with those of previous methods. The main contribution is an improved fitness function for GA, capable of improving the objective function while directing the PQ constraints toward the permissible region using fuzzy approximate reasoning. This method leads to computing the (near) global solution with a lower probability of getting stuck at a local optimum and weak dependency on initial conditions while avoiding numerical problems in large systems.
\end{abstract}

Index Terms-Capacitor, fuzzy logic (FL), genetic algorithm (GA), harmonics, placement, power flow and optimization, power quality (PQ), sizing.

\section{INTRODUCTION}

$\mathbf{T}$ HE problem of shunt capacitor allocation in distribution networks for reactive power compensation, voltage regulation, power factor correction, and power/energy loss reduction has been extensively researched and documented in literature [1]-[4]. However, limited attention is given to this problem in the presence of voltage and current harmonics.

With the increasing application of nonlinear loads and devices causing voltage and current harmonics in distribution networks, special attention should be paid to the placement and sizing of capacitors in such distorted systems. This is due to resonances, increased losses, extensive reactive power demand, and overvoltages at fundamental and harmonic frequencies.

Some recent publications have taken into account the presence of distorted voltages for solving the capacitor placement problem. These investigations include: exhaustive search [5], local variations [6], mixed integer-nonlinear programming [7],

Manuscript received December 22, 2005; revised April 23, 2007. This work was supported by Tehran Public Service. Paper no. TPWRD-00741-2005.

The authors are with the Department of Electrical and Computer Engineering, Curtin University of Technology, Perth 6845, Australia.

Color versions of one or more of the figures in this paper are available online at http://ieeexplore.ieee.org.

Digital Object Identifier 10.1109/TPWRD.2007.911185
[8], heuristic methods [9], maximum sensitivities selection [10]-[12], fuzzy set theory [13], [14], and genetic algorithms (GAs) [15]. Some of these documents [5]-[10], [13] ignore the couplings between harmonic voltages and currents. References [11], [12], [14], and [15] use a harmonic power flow that considers harmonic couplings caused by the nonlinear loads. Reference [8] addresses the problem under unbalanced three-phase conditions.

Most of these techniques are fast, but they suffer from the inability to escape local optimal solutions. Simulated annealing (SA), tabu search (TS), and GAs are three near global optimization techniques that have demonstrated fine capabilities for capacitor placement [1]-[4], but the computational burden is heavy.

Fuzzy logic (FL) has shown good results for capacitor bank allocation when combined with GAs under sinusoidal operating conditions [1], [2], [16], [17]. However, FL has been mainly used to select the most adequate buses for capacitor placement and, hence, to reduce the search space for GA under sinusoidal operating conditions [2].

This paper proposes a GA in conjunction with FL (GA-FL) to formulate the capacitor placement and sizing problem in the presence of voltage and current harmonics, taking into account a limited number of fixed capacitor banks at each bus. Operational and power-quality (PQ) constraints include the bounds of root mean square (rms) voltage $\mathrm{THD}_{\mathrm{v}}$, the number/size of installed capacitors, and harmonic parallel resonances. In the proposed method, the suitability of $\mathrm{THD}_{\mathrm{v}}$ and voltage are defined for each chromosome based on fuzzy approximate reasoning. These variables represent the level of constraints satisfaction and are used with cost index (objective function) to determine the fitness function. Fuzzy approximate reasoning is used to calculate the fitness function considering the uncertainty of decision making based on constraints and objective function. This method improves the evolution process of GA, lowering the probability of getting stuck at local optimum and avoiding numerical problems [18]-[20].

\section{Newton-BASEd HARMONIC POWER Flow}

For modeling a distribution system with nonlinear loads at fundamental and harmonic frequencies, the formulation and notations of [21] and [22] are used. Linear loads are modeled as shunt admittances at harmonic frequencies [5]. Nonlinear loads with given $\mathrm{v}-\mathrm{i}$ characteristics (either in the frequency or time domain) represent the coupling between harmonic voltages and currents. These loads are modeled as shunt harmonic current sources and are updated at every iteration of the harmonic power flow. 
The system solution (with linear and nonlinear loads under balanced nonsinusoidal three-phase conditions) is achieved by forcing total (fundamental and harmonic) mismatch active and reactive powers as well as mismatch active and reactive fundamental and harmonic currents to zero using the Newton-Raphson method.

\section{PROBLEM Formulation}

Fixed capacitor banks are treated as variable shunt reactances with discrete values, and capacitor placement is possible for $\mathrm{NC}$ number of buses.

\section{A. Constraints}

Voltage constraints will be taken into account by specifying upper (e.g., $V^{\max }=1.1$ p.u.) and lower (e.g., $V^{\mathrm{min}}=0.9$ p.u.) bounds of rms voltage $(n=$ total number of buses, $i=$ bus number, $\mathrm{h}=$ harmonic order)

$$
V^{\min } \leq \sqrt{\sum_{h}\left(V_{i}^{(h)}\right)^{2}} \leq V^{\max } \quad \text { for } \quad i=1, \ldots, n .
$$

The voltage distortion is considered by specifying the maximum total harmonic distortion $\left(\mathrm{THD}_{\mathrm{v}}\right)$ of voltages

$$
\begin{aligned}
\operatorname{THD}_{v, i} & =\left(\left[\sqrt{\sum_{h \neq 1}\left(V_{i}^{(h)}\right)^{2}}\right] / V_{i}^{(1)}\right) \cdot 100 \% \\
& \leq \mathrm{THD}_{v}^{\max } \text { for } i=1, \ldots, n .
\end{aligned}
$$

Bounds for (1) and (2) are specified by the IEEE-519 standard [23]. Let $u^{\max }$ denote the maximum number of capacitor units allowed at each bus. The number of capacitors at bus $i$ is limited by

$$
u=u_{f i} \leq u^{\max } \quad \text { for } \quad i \in \mathrm{MC}
$$

where $u_{f i}$ denotes the number of fixed capacitor banks at bus $\mathrm{i}$ and $\mathrm{MC}$ is the set of possible buses for capacitor placement.

\section{B. Objective Function (Cost Index)}

The objective function ("cost") used for capacitor placement in the presence of harmonics is [5], [10], [14], and [15]

$$
\begin{aligned}
\min F= & F_{\text {loss }}+F_{\text {cap } .}+F_{\text {capacity }} \\
= & K_{E} T P_{\text {loss }}\left(V^{(1)}, \ldots, V^{(L)}, C\right)+\sum_{i \varepsilon M C} K_{c f p} C_{f i} \\
& +K_{A} P_{\text {loss }}\left(V^{(1)}, \ldots, V^{(L)}, C\right)
\end{aligned}
$$

where

$$
\begin{array}{ll}
F_{\text {loss }} & \text { energy loss cost; } \\
F_{\text {cap. }} & \text { cost of fixed capacitors; } \\
F_{\text {capacity }} & \begin{array}{l}
\text { cost corresponding to power losses (e.g., used } \\
\text { capacity of the system); }
\end{array} \\
P_{\text {loss }} & \text { total system losses; }
\end{array}
$$

$V^{(h)} \quad$ bus voltage vector at harmonic h;

$L \quad$ highest order of considered harmonics;

C size of connected capacitors;

$T \quad$ duration of load (h/yr);

$M C \quad$ set of possible shunt capacitor buses;

$K_{\mathrm{cfp}} \quad$ cost per unit of fixed capacitance [15, Table I];

$K_{E} \quad$ cost per megawatt-hour (e.g., $\mathrm{K}_{\mathrm{E}}=50$ U.S. \$/MWh [10]);

$K_{A} \quad$ saving per megawatt for reduction in losses (e.g., $\mathrm{K}_{\mathrm{A}}=120,000$ U.S. \$/MW [10]).

Total losses can be computed using the Newton-based harmonic power-flow outputs

$$
P_{\mathrm{loss}}=\sum_{h=1}^{L}\left[\sum_{i=1}^{n} \sum_{j=1}^{n} V_{i}^{(h)} V_{j}^{(h)} Y_{i j}^{(h)} \cos \left(\theta_{i}^{(h)}-\theta_{j}^{(h)}-\delta_{i j}^{(h)}\right)\right]
$$

where $V_{i}^{(h)}$ and $\theta_{i}^{(h)}$ are the magnitude and phase of the $h$ th harmonic voltage at bus $\mathrm{i}$, and $Y_{i j}^{(h)}$ and $\delta_{i j}^{(h)}$ are the magnitude and phase of the $h$ th harmonic line admittance between buses i and $\mathrm{j}$, respectively.

\section{SOlution Method}

This paper proposes a new hybrid approach based on GA and fuzzy approximate reasoning for the optimal placement and sizing of capacitor banks in distorted distribution networks with harmonic voltages and currents.

GAs use biological evolution and population genetics to search and arrive at a high-quality (near) global solution. The required design variables are encoded into a binary string as a set of genes corresponding to chromosomes in biological systems. Unlike the traditional optimization techniques that require one starting point, they use a set of points as the initial conditions. Each point is called a chromosome. A group of chromosomes (e.g., equal to 250 in this paper) is called a population. During each iterative procedure (referred to as a generation), a new population is generated using three GA operators (namely reproduction, crossover, and mutation).

Fuzzy set theory (FST) contains a set of rules which are developed from qualitative descriptions. When the suitability of $\mathrm{THD}_{\mathrm{v}}$ and voltage and the cost of the distribution system are studied, an engineer can choose the most appropriate combination of capacitor banks. For example, it is intuitive that a distribution system with a high suitability of $\mathrm{THD}_{\mathrm{v}}$ and voltage, having a low cost is highly desirable. Fuzzy rules are defined to determine the suitability of each chromosome ( $\left.S_{\text {chrom }}\right)$ and may be executed with some degree using fuzzy inference. $S_{\text {chrom }}$ is used as the fitness function in the GA to further improve the evolution process, reducing the probability of getting stuck at a local optimum.

\section{A. Structure of Chromosomes}

In this work, the chromosome for GA consists of a sequence of NC substrings as shown in Fig. 1, where NC denotes the 


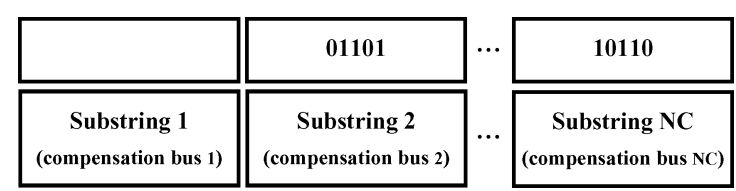

Fig. 1. Chromosome structure for the GA.

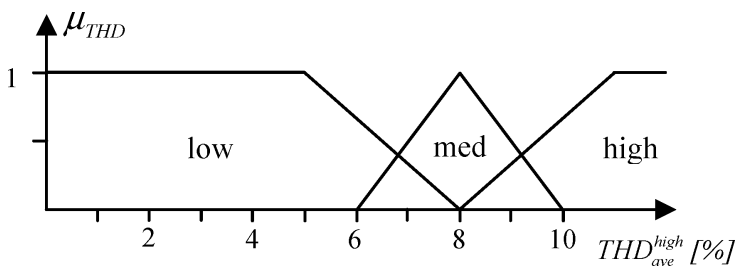

Fig. 2. Membership functions for the average of unacceptable (high) $\mathrm{THD}_{\mathbf{v}}$ values (6).

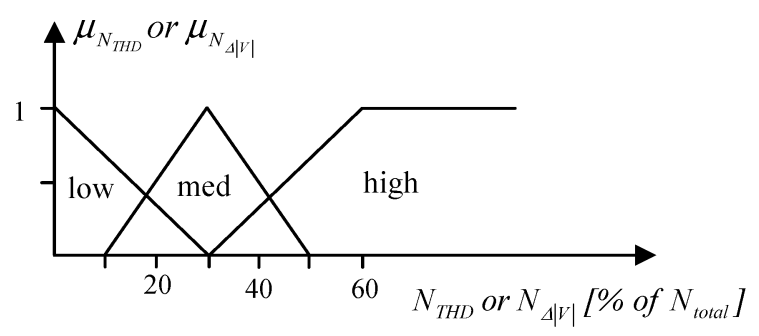

Fig. 3. Membership functions for a number of buses with unacceptable $\mathrm{THD}_{\mathrm{v}}$ or voltage.

TABLE I

DECISION MATRIX FOR DETERMINING SUITABILITY OF THD $v($ AND $V$ )

\begin{tabular}{|c|c|c|c|c|}
\hline \multicolumn{2}{|c|}{ AND } & \multicolumn{3}{|c|}{$T H D_{v}($ or $\Delta|V|)$} \\
\cline { 3 - 5 } \multicolumn{2}{|c|}{} & low & med & high \\
\hline \multirow{3}{*}{$\begin{array}{c}N_{T H D} \\
\left.\text { (or } N_{\Delta|V|}\right)\end{array}$} & low & high & med & med \\
\cline { 2 - 5 } & med & med & low & low \\
\cline { 2 - 5 } & high & med & low & low \\
\hline
\end{tabular}

number of possible compensation buses for capacitor placement in the entire feeder. The binary substrings indicate the number of the installed capacitor units at the bus under consideration which is limited to $u^{\max }$.

\section{B. Proposed Fuzzy Fitness (Suitability) Function}

The suitability level of each chromosome $\left(S_{\text {chrom }}\right)$ is computed by defining fuzzy membership functions for the suitability of total harmonic distortion $\left(\mu_{S_{\mathrm{THD}}}\right)$, voltage $\left(\mu_{S_{V}}\right)$, and cost index $\left(\mu_{\text {cost }}\right)$.

A fuzzy expert system (FES) uses the number of buses with high $\mathrm{THD}_{\mathrm{v}}$ and the average of $\mathrm{THD}_{\mathrm{v}}$ at these buses to determine the suitability of $\mathrm{THD}_{\mathrm{v}}$. A similar method is used to determine the suitability of voltage.

A concern in the development of fuzzy expert systems is the assignment of appropriate membership functions which could

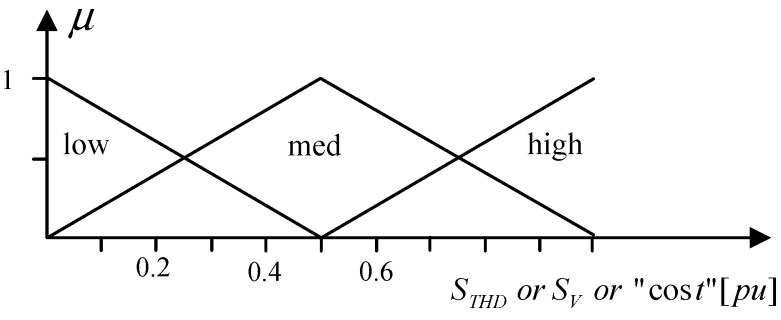

Fig. 4. Membership functions for the suitability of $\mathrm{THD}_{v}, V$ and "cost."

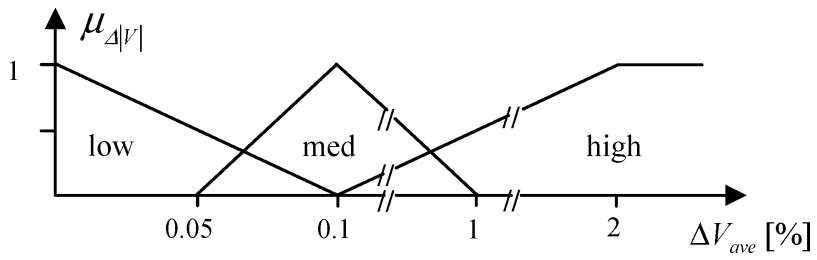

Fig. 5. Membership functions for the average of unacceptable voltage deviation values (8).

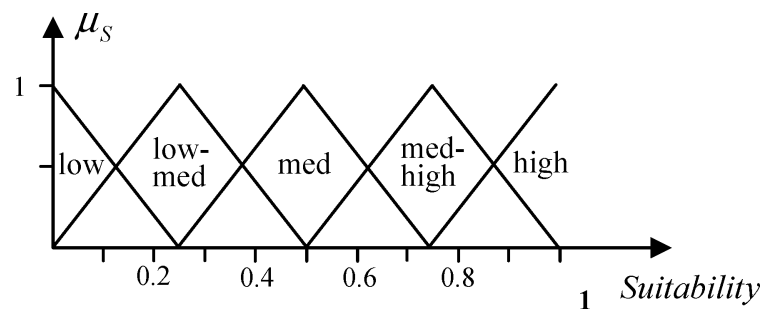

Fig. 6. Membership functions for $S_{\text {chrom }}$.

be performed based on intuition, rank ordering, or probabilistic methods. However, the choice of membership degree in the interval $[0,1]$ does not matter, as it is the order of magnitude that is important [1], [24].

1) Suitability of $\mathrm{THD}_{\mathrm{v}}\left(\mathrm{S}_{\mathrm{THD}}\right)$ : For a given chromosome, define the average of unacceptable $\mathrm{THD}_{\mathrm{v}}$ values

$$
\mathrm{THD}_{\text {ave }}^{\text {high }}=\sum_{j=1}^{N_{\mathrm{THD}}} \mathrm{THD}_{j} / N_{\mathrm{THD}}
$$

where $N_{\text {THD }}$ is the number of buses with high total voltage harmonic distortions (i.e., $\mathrm{THD}_{\mathrm{j}}>\mathrm{THD}_{\mathrm{v}}^{\max }$ ). The following steps are performed to compute $S_{\mathrm{THD}}$ :

- fuzzification of $\mathrm{THD}_{\text {ave }}^{\text {high }}$ and $N_{\mathrm{THD}}$ (based on membership functions of Figs. 2 and 3, respectively) to compute the corresponding membership values $\left(\mu_{\mathrm{THD}}\right.$ and $\left.\mu_{N_{\mathrm{THD}}}\right)$;

- fuzzy inferencing and defuzzification based on the decision matrix of Table I, the membership function of Fig. 4 and the Mamdani-max-prod implication method

$$
S_{\mathrm{THD}}=\sum \bar{y} \mu_{N_{\mathrm{THD}}} \mu_{\mathrm{THD}} / \sum \mu_{N_{\mathrm{THD}}} \mu_{\mathrm{THD}} .
$$


TABLE II

Proposed Decision Matrix for Determining the Suitability of a Chromosome $\left(S_{\text {chrom }}\right)$

\begin{tabular}{|c|c|c|c|c|c|c|c|c|c|c|}
\hline \multirow{2}{*}{\multicolumn{2}{|c|}{ AND }} & \multicolumn{9}{|c|}{$S_{T H D}$} \\
\hline & & \multirow{2}{*}{\multicolumn{3}{|c|}{$\frac{\text { low }}{\text { "cost } t "}$}} & \multirow{2}{*}{\multicolumn{3}{|c|}{$\frac{\text { med }}{\text { "cost" }}$}} & \multirow{2}{*}{\multicolumn{3}{|c|}{$\begin{array}{l}\text { high } \\
\text { "cost" }\end{array}$}} \\
\hline \multirow{9}{*}{$S_{V}$} & \multirow[b]{3}{*}{ low } & & & & & & & & & \\
\hline & & low & med & high & low & med & high & low & med & high \\
\hline & & low-med & low & low & med & low-med & low & med-high & med & low-med \\
\hline & \multirow[b]{3}{*}{ med } & \multicolumn{3}{|c|}{ "cost" } & \multicolumn{3}{|c|}{ "cost $"$} & \multicolumn{3}{|c|}{ "cost $"$} \\
\hline & & low & med & high & low & med & high & low & med & high \\
\hline & & med & low-med & low & med-high & med & low-med & med-high & med & med \\
\hline & \multirow[b]{3}{*}{ high } & \multicolumn{3}{|c|}{$" \cos t "$} & \multicolumn{3}{|c|}{ "cost" } & \multicolumn{3}{|c|}{ "cost" } \\
\hline & & low & med & high & low & med & high & low & med & high \\
\hline & & med & low-med & low & med-high & med-high & med & high & high & med-high \\
\hline
\end{tabular}

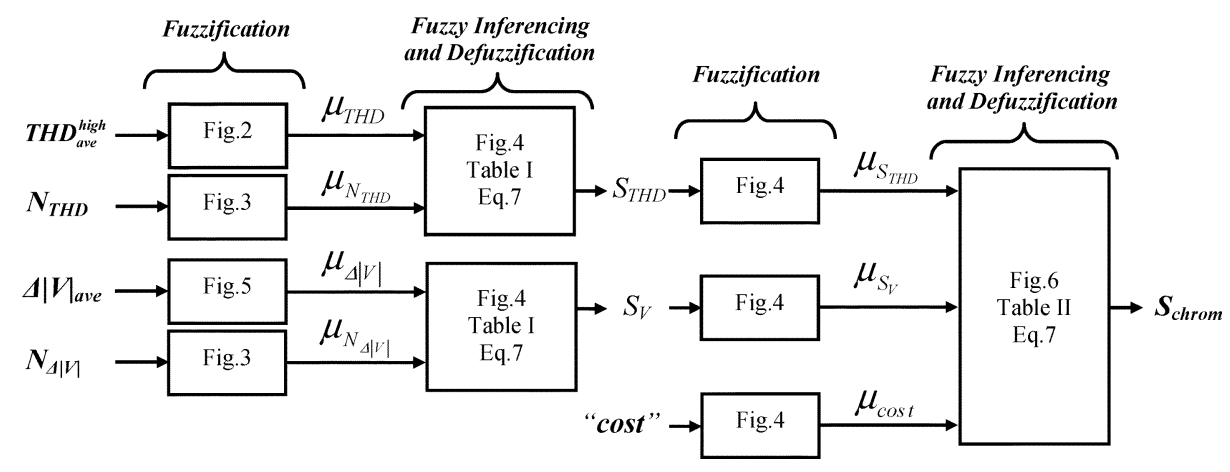

Fig. 7. Proposed fuzzy expert system (FES) to determine the suitability of a chromosome $\left(S_{\text {chrom }}\right)$ for capacitor placement from total harmonic distortion $\left(\mathrm{THD}_{\mathrm{v}}\right)$, voltage deviation $\left(\Delta|V|_{\mathrm{ave}}\right)$, "cost," number of buses with unacceptable $\mathrm{THD}_{\mathrm{v}}\left(\mathrm{N}_{\mathrm{THD}}\right)$ and unacceptable $|\mathrm{V}|\left(\mathrm{N}_{\Delta|\mathrm{V}|}\right)$.

2) Suitability of Voltage $\left(S_{V}\right)$ : For a given chromosome, define the average of unacceptable voltage deviation values as
- fuzzy inferencing and defuzzification [using the decision matrix of Table II, Fig. 6 and (7)] to determine the suitability of the chromosome $\left(S_{\text {chrom }}\right)$.

\section{Genetic Operators}

Three stochastic transition rules are applied to each chromosome during the generation procedure to generate a new improved population from an old one.

1) Reproduction - a probabilistic process for selecting two parent strings from the population of strings on the basis of a "roulette-wheel" mechanism, using their fitness values.

2) Crossover - the process of selecting a random position in the chromosome and substrings (called the crossover point) and swapping the characters either right or left of this point with another similarly partitioned string. The probability of parent-chromosomes crossover is assumed to be between 0.6 and 1.0.

3) Mutation - the process of random modification of a string position by changing " 0 " to " 1 " or vice-versa, with a small probability. In this paper, the probability of mutation is assumed to be between 0.01 and 0.1 .

\section{Solution Methodology}

The shunt capacitor placement and sizing problem in the presence of linear and nonlinear loads is solved using the proposed GA-FL algorithm of Fig. 8, as follows:

Step 1) input system parameters and the initial population.

Step 2) (Fuzzy Fitness/Suitability): Perform the following for all chromosomes (Fig. 7): 


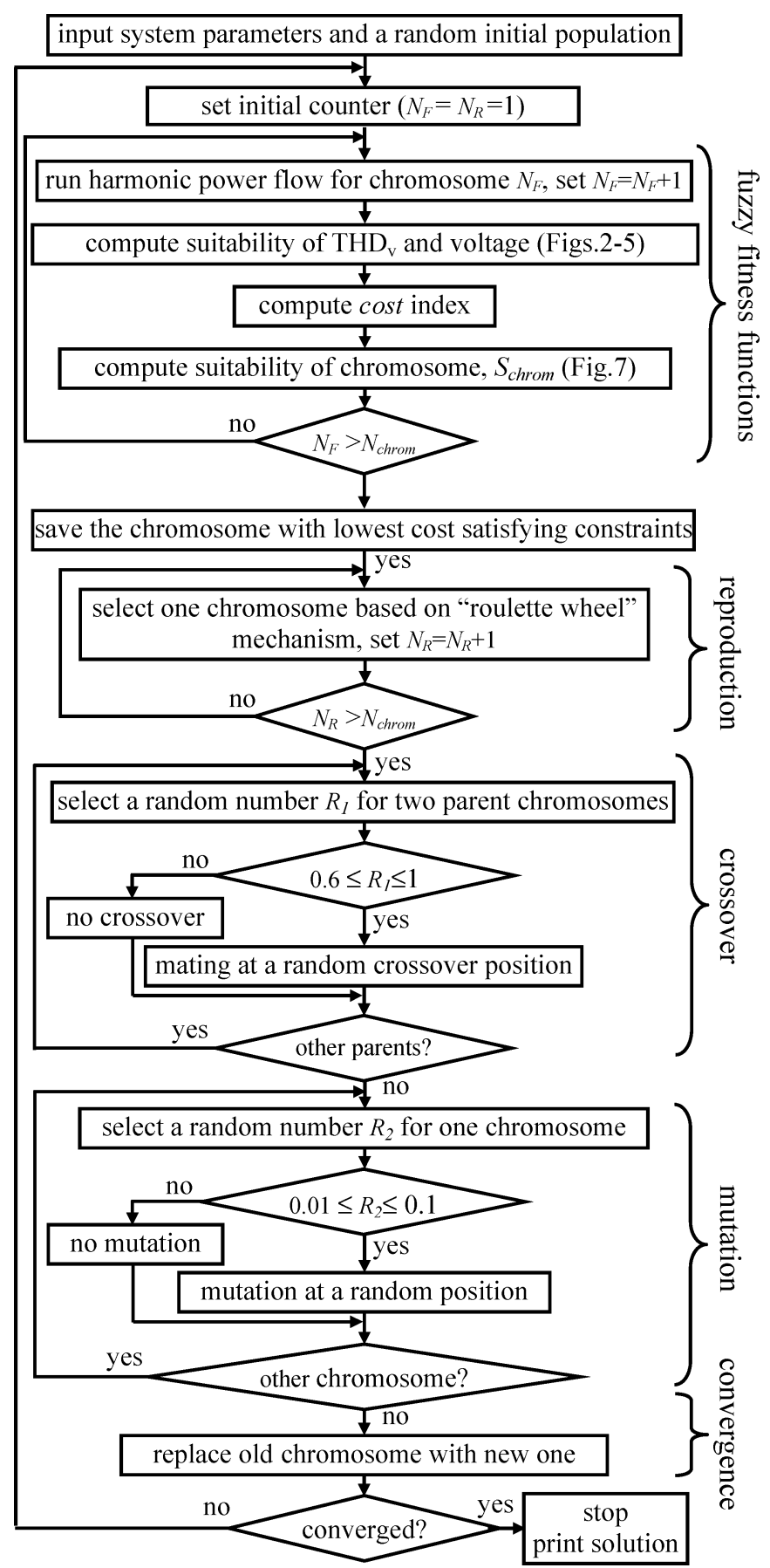

Fig. 8. Proposed GA-FL method for optimal placement and sizing of capacitor banks in the presence of harmonics.

Step 2A) Run the harmonic power flow.

Step 2B) Compute suitability of $\mathrm{THD}_{v}$ and voltage [Figs. 2-5, Table I and (6)-(8)].

Step 2C) Compute the cost index.

Step 2D) Compute the suitability of chromosome $S_{\text {chrom }}$ [Fig. 6, Table II, and (7)].

Step 3) (Reproduction Process): Select a new combination of chromosomes by spinning the "roulette wheel."

Step 4) (Crossover Process): Select a random number for mating two parent chromosomes. If it is between 0.6 and 1.0, then combine the two parents and generate two

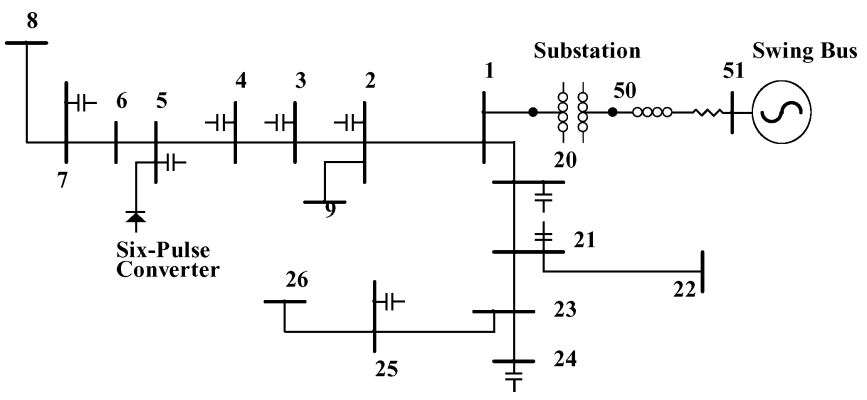

Fig. 9. Single-line diagram of the 18-bus IEEE distorted system [11], [12], [14], [15], [25] used for simulation and analysis.

offspring. Otherwise, transfer the chromosomes with no crossover.

Step 5) (Mutation Process): Select a random number for the mutation of one chromosome. If it is between 0.01 and 0.1 , then apply the mutation process at a random position. Otherwise, transfer the chromosome with no mutation.

Step 6) (Updating Populations): Replace the old population with the improved population generated by Steps 2) to 5). Check all chromosomes and save the one with minimum cost, satisfying all constraints.

Step 7) (Convergence): If all chromosomes are the same or the maximum number of iterations is achieved $\left(N_{\max }=40\right)$, then print the solution and stop, else go to Step 2).

\section{ApPlicAtion OF THE Method}

\section{A. Simulation of the 18-Bus IEEE Distorted System}

The proposed GA-FL method (Fig. 8) and previous capacitor placement techniques (MSS [10], [11], MSS-LV [12], fuzzy [14], genetic [15]) are applied to the 23-kV, 18-bus distorted IEEE distribution system. Line and data specifications are given in [25]. A single-line diagram of the system is shown in Fig. 9. The six-pulse rectifier (with $\mathrm{P}=0.3$ p.u. $=3 \mathrm{MW}$ and $\mathrm{Q}=$ 0.226 p.u. $=2.26 \mathrm{MVAr}$ ) causes a maximum voltage $\mathrm{THD}_{\mathrm{v}}$ of $8.486 \%$ (column 2 of Table III).

Simulation results for the MSS, MSS-LV, fuzzy and genetic algorithm (GA) are listed in columns 3 to 6 of Table III, respectively. Among these previously proposed algorithms, the GA approach results in a near global solution with the best yearly benefit of U.S.\$ 18949 (column 6 of Table III). Note that MSS (a local search algorithm) results in a higher benefit (i.e., U.S.\$ 20653 per year) but it does not limit $\mathrm{THD}_{\mathrm{v}}$ to the desired level of 5\% (column 3 of Table III).

The proposed GA-FL approach of Fig. 8 is also applied to this system for optimal placement and sizing of capacitor banks. The results show a yearly benefit of U.S.\$19550 (last row of Table III) and the maximum voltage $\mathrm{THD}_{\mathrm{v}}$ is limited to $4.98 \%$ (column 7 of Table III). Compared to the GA approach, the total annual benefit is increased by U.S. $\$ 600$ (i.e., $3.2 \%$ ) and the total allocated capacitance is decreased by 0.015 p.u.

\section{B. Simulation of the 123-Bus IEEE Distorted System}

The GA [15] and proposed GA-FL (Fig. 8) methods are applied to the 4.16-kV, 123-bus distorted IEEE radial distribu- 
TABLE III

Simulation Results of MSS [11], MSS-LV [12], FuZZy Set [14], GeNetic Algorithm [15] AND the Proposed GA-FL APPROACH FOR THE 18-BuS, DiSTORTED IEEE DISTRIBUTION SYSTEM OF FIG. 9 (PER UNIT VA $=10 \mathrm{MVA}$, PER UNIT V $=23 \mathrm{kV}$, swing bus voltage $=1.05$ p.u.)

\begin{tabular}{|c|c|c|c|c|c|c|}
\hline \multirow[b]{2}{*}{ optimization method } & \multirow[b]{2}{*}{$\begin{array}{c}\text { before * } \\
\text { optimization }\end{array}$} & \multicolumn{3}{|c|}{ local optimization } & \multicolumn{2}{|c|}{ (near) global optimization } \\
\hline & & $\begin{array}{l}\text { after MSS** } \\
\text { optimization }\end{array}$ & $\begin{array}{l}\text { after MSS-LV** } \\
\text { optimization }\end{array}$ & $\begin{array}{l}\text { after fuzzy** } \\
\text { optimization }\end{array}$ & $\begin{array}{r}\text { after GA** } \\
\text { optimization }\end{array}$ & $\begin{array}{l}\text { after GA-FL** } \\
\text { optimization }\end{array}$ \\
\hline \multirow{10}{*}{$\begin{array}{l}\text { capacitor bank } \\
\text { locations [pu] }\end{array}$} & $\mathrm{Q} 2=0.105$ & $\mathrm{Q} 2=0.030$ & $\mathrm{Q} 2=0.120$ & $\mathrm{Q} 2=0.015$ & $\mathrm{Q} 2=0.030$ & $\mathrm{Q} 2=0.030$ \\
\hline & $\mathrm{Q} 3=0.060$ & $\mathrm{Q} 3=0.090$ & $\mathrm{Q} 3=0.060$ & $\mathrm{Q} 3=0.030$ & $\mathrm{Q} 3=0.000$ & $\mathrm{Q} 3=0.000$ \\
\hline & $\mathrm{Q} 4=0.060$ & $\mathrm{Q} 4=0.180$ & $\mathrm{Q} 4=0.180$ & $\mathrm{Q} 4=0.060$ & $\mathrm{Q} 4=0.165$ & $\mathrm{Q} 4=0.195$ \\
\hline & $\mathrm{Q} 5=0.180$ & $\mathrm{Q} 5=0.240$ & $\mathrm{Q} 5=0.240$ & $\mathrm{Q} 5=0.240$ & $\mathrm{Q} 5=0.330$ & $\mathrm{Q} 5=0.300$ \\
\hline & $\mathrm{Q} 7=0.060$ & $\mathrm{Q} 7=0.120$ & $\mathrm{Q} 7=0.120$ & $\mathrm{Q} 7=0.210$ & $\mathrm{Q} 7=0.105$ & $\mathrm{Q} 7=0.105$ \\
\hline & $\mathrm{Q} 20=0.060$ & $\mathrm{Q} 20=0.090$ & $\mathrm{Q} 20=0.090$ & $\mathrm{Q} 20=0.090$ & $\mathrm{Q} 20=0.060$ & $\mathrm{Q} 20=0.090$ \\
\hline & $\mathrm{Q} 21=0.120$ & $\mathrm{Q} 21=0.120$ & $\mathrm{Q} 21=0.120$ & $\mathrm{Q} 21=0.120$ & $\mathrm{Q} 21=0.090$ & $\mathrm{Q} 21=0.075$ \\
\hline & $\mathrm{Q} 24=0.150$ & $\mathrm{Q} 24=0.000$ & $\mathrm{Q} 24=0.000$ & $\mathrm{Q} 24=0.000$ & $\mathrm{Q} 24=0.015$ & $\mathrm{Q} 24=0.015$ \\
\hline & $\mathrm{Q} 25=0.090$ & $\mathrm{Q} 25=0.030$ & $\mathrm{Q} 25=0.000$ & $\mathrm{Q} 25=0.000$ & $\mathrm{Q} 25=0.015$ & $\mathrm{Q} 25=0.015$ \\
\hline & $\mathrm{Q} 50=0.120$ & $\mathrm{Q} 50=0.000$ & $\mathrm{Q} 50=0.000$ & $\mathrm{Q} 50=0.000$ & $\mathrm{Q} 50=0.030$ & $\mathrm{Q} 50=0.000$ \\
\hline total capacitor [pu] & $Q t=1.005$ & $Q t=0.900$ & $Q t=0.930$ & $Q t=0.765$ & $\mathrm{Qt}=\mathbf{0 . 8 4 0}$ & $Q t=0.825$ \\
\hline minimum voltage [pu] & 1.029 & 1.016 & 1.013 & 0.998 & 1.003 & 1.005 \\
\hline maximum voltage $[\mathrm{pu}]$ & 1.055 & 1.056 & 1.059 & 1.050 & 1.050 & 1.050 \\
\hline maximum $\mathrm{THD}_{\mathrm{v}}[\%]$ & 8.486 & 6.370 & 4.720 & 4.899 & 4.883 & 4.982 \\
\hline losses [kW] & 282.93 & 246.43 & 250.37 & 257.46 & 249.31 & 248.18 \\
\hline capacitor cost [\$/year] & $1,978.20$ & $1,692.00$ & $2,206.80$ & $1,458.30$ & $1,788.75$ & $1,817.55$ \\
\hline total cost [\$ / year] & $159,853.14$ & $139,199.94$ & $141,913.26$ & $145,120.98$ & $140,903.73$ & $140,302.8$ \\
\hline benefits [\$ / year] & & $20,653.6$ & $17,939.88$ & $14,732.16$ & $18,949.41$ & $19,550.34$ \\
\hline
\end{tabular}

*) Simulation results before any optimization and capacitor placement [25].

**) Simulation results after MSS [11], MSS-LV [12], fuzzy set [14], and genetic [15] optimizations (capacitors were removed before optimization).

TABLE IV

NONLINEAR LOAD DATA FOR THE IEEE 123-BUS SYSTEM

\begin{tabular}{|c|l|c|c|}
\hline nonlinear bus & nonlinear load type (Table A1) & kW & kVAR \\
\hline 6 & six-pulse variable frequency drive & 15 & 10 \\
7 & six-pulse 3 & 15 & 10 \\
10 & six-pulse 2 & 24 & 3 \\
19 & six-pulse 2 & 24 & 3 \\
26 & six-pulse 2 & 15 & 10 \\
30 & six-pulse 1 & 24 & 3 \\
33 & six-pulse 3 & 24 & 3 \\
42 & six-pulse 3 & 15 & 10 \\
49 & six-pulse variable frequency drive & 60 & 45 \\
52 & six-pulse 1 & 24 & 3 \\
64 & six-pulse 1 & 24 & 3 \\
71 & six-pulse variable frequency drive & 15 & 10 \\
73 & six-pulse 3 & 24 & 3 \\
87 & six-pulse 2 & 60 & 45 \\
89 & six-pulse 1 & 24 & 3 \\
92 & six-pulse 1 & 24 & 3 \\
94 & six-pulse variable frequency drive & 15 & 10 \\
95 & six-pulse 1 & 24 & 3 \\
106 & six-pulse variable frequency drive & 15 & 10 \\
113 & six-pulse 2 & 24 & 3 \\
\hline
\end{tabular}

tion network of Fig. 11 [26]. To introduce harmonic distortion, 20 nonlinear loads (Table IV) with different harmonic spectra (Table VI) are included. These loads are modeled as harmonic current sources and the coupling between harmonics is not considered. The high penetration of these nonlinear loads causes a maximum $\mathrm{THD}_{\mathrm{v}}$ of $8.03 \%$ (column 2, Table V).

The results of the proposed GA-FL approach show a 5.5\% increase in total annual benefits compared with those generated by the GA method (last row of Table V) while the maximum $\mathrm{THD}_{\mathrm{v}}$ is significantly limited to $2.76 \%$.
TABLE V

Simulation Results of Genetic Algorithm [15] AND the PROPOSED GA-FL APPROACH FOR THE 123-BUS, DISTORTED IEEE DISTRIBUTION SYSTEM

\begin{tabular}{|l|c|c|c|}
\hline \multirow{2}{*}{ optimization method } & $\begin{array}{c}\text { before } \\
\text { optimization }\end{array}$ & $\begin{array}{c}\text { GA } \\
\text { optimization }\end{array}$ & $\begin{array}{c}\text { GA-FL } \\
\text { optimization }\end{array}$ \\
\hline \multirow{2}{*}{$\begin{array}{c}\text { capacitor bank } \\
\text { locations [kW] }\end{array}$} & $\mathrm{Q} 83=200$ & $\mathrm{Q} 26=150$ & $\mathrm{Q} 42=300$ \\
\cline { 2 - 4 } & $\mathrm{Q} 88=50$ & $\mathrm{Q} 42=300$ & $\mathrm{Q} 52=300$ \\
\cline { 2 - 4 } & & $\mathrm{Q} 72=150$ & $\mathrm{Q} 72=300$ \\
\hline total capacitor [kW] & $\mathbf{Q t}=\mathbf{3 5 0}$ & $\mathbf{Q 7 6}=300$ & $\mathrm{Q} 105=150$ \\
\hline minimum voltage [pu] & 0.874 & 0.904 & $\mathbf{Q t}=\mathbf{1 0 5 0}$ \\
\hline $\begin{array}{l}\text { maximum voltage } \\
\text { [pu] }\end{array}$ & 0.980 & 0.980 & 0.915 \\
\hline maximum THD $[\%]$ & $\mathbf{8 . 0 3 1 9}$ & $\mathbf{3 . 1 0 1 8}$ & $\mathbf{2 . 7 6 0 3}$ \\
\hline losses [kW] & 94.96 & 82.021 & 81.28 \\
\hline capacitor cost [\$/year] & 125 & 360 & 390 \\
\hline total cost [\$/year] & $53,114.5$ & $46,127.72$ & $45,744.24$ \\
\hline benefits [\$ year] & & $\mathbf{6 , 9 8 6 . 8}$ & $\mathbf{7 , 3 7 0 . 3}$ \\
\hline
\end{tabular}

\section{ANALYSIS AND CONVERGENCE CRITERION}

The generations of the GA-FL algorithm are continued until all chromosomes of the population become equal or the maximum number of generations is achieved. The initial conditions for (4) (i.e., the initial capacitor values) do not usually reside inside the permissible solution region. In this paper, a GA-FL approach is used to minimize the objective function while directing the constraints toward the permissible region.

To select the parent population at each generation, a fuzzy expert system (Fig. 7) is used to compute the fitness function of each chromosome considering the uncertainty of decision making based on the objective function and constraints. As a 


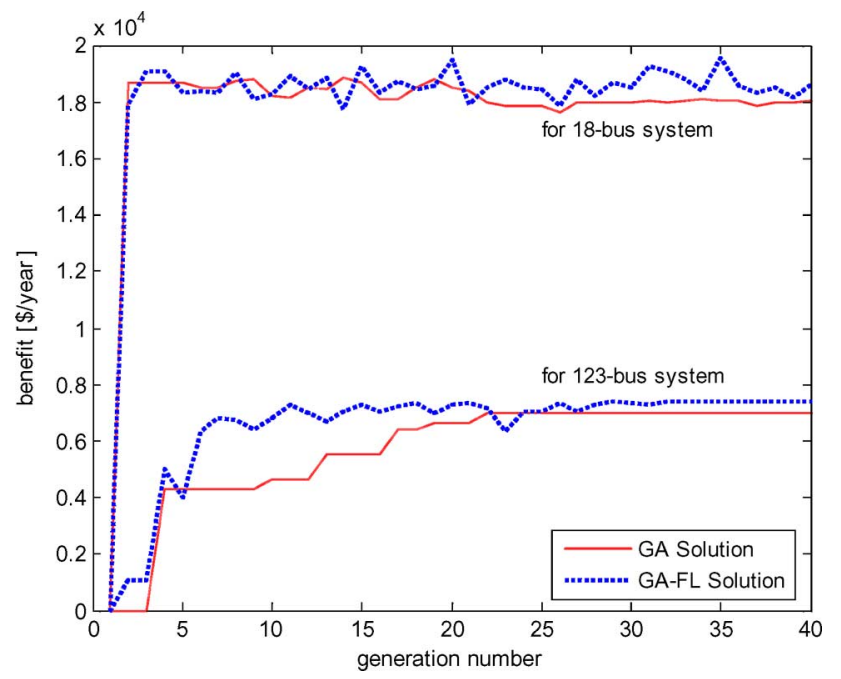

Fig. 10. Solution progress of the proposed GA-FL and the GA methods for the 18-bus (Table III) and 123-bus, distorted IEEE distribution systems (Table V).

result, new generations have a higher probability of capturing the global solution.

As demonstrated in Fig. 10, the relatively narrow search band of the conventional GA does not allow a large variation of chromosomes between generations and, thus, it is more difficult to escape from local optima. For the 18-bus and 123-bus systems, the solution is trapped at a near global point after the 14th and 22nd iterations, respectively. In the proposed GA-FL approach, there is more variety in the generated parent population as the chromosome evaluation is based on FL. The larger search space (allowing large variations of benefits in consecutive iterations) has resulted in a better near global solution at the 35th and 29th iterations for the 18-bus and 123-bus systems, respectively.

The inclusion of objective function and PQ constraints will automatically eliminate all solutions generating extreme values for voltages and/or currents and prevents fundamental and harmonic parallel resonances.

\section{CONCLUSION}

A GA, in conjunction with fuzzy logic (GA-FL), is proposed for the discrete optimization problem of fixed shunt capacitor placement and sizing in the presence of voltage and current harmonics. Power losses, energy losses, and the cost of fixed capacitors are used as the objective function. The PQ limits of IEEE-519 standard, maximum, and minimum of bus rms voltages and the allowed number of capacitor banks at each bus are considered as constraints. The main contributions of the proposed GA-FL approach are:

- PQ and cost index of the power system are improved simultaneously by optimal capacitor placement;

- a fuzzy expert system is used to improve the evolution process of GA (selecting the most suitable capacitor locations and sizes) by defining fitness (suitability) functions for each chromosome (computed from membership values of suitability of $\operatorname{THD}_{v}$, suitability of voltage, and "cost");

- the uncertainty of decision making based on the objective function and suitability of constraints is considered in

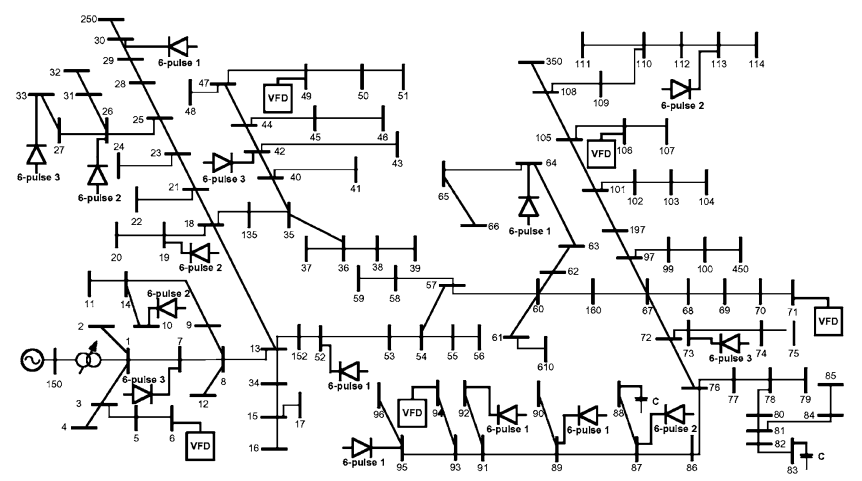

Fig. 11. IEEE 123-bus distribution system [15] with 20 nonlinear loads.

TABLE VI

HARMONIC SPECTRA OF NONLINEAR LOADS

\begin{tabular}{|c|c|c|c|c|c|c|c|c|}
\hline \multirow{3}{*}{$\frac{\bar{t}}{0}$} & \multicolumn{8}{|c|}{ nonlinear load } \\
\hline & \multicolumn{2}{|c|}{ six-pulse1 } & \multicolumn{2}{|c|}{ six-pulse2 } & \multicolumn{2}{|c|}{ six-pulse 3} & \multicolumn{2}{|c|}{ six-pulse VFD } \\
\hline & $\begin{array}{l}\mathrm{mag} \\
{[\%]}\end{array}$ & $\begin{array}{c}\mathrm{ph} \\
{[\mathrm{deg}]}\end{array}$ & $\begin{array}{c}\mathrm{mag} \\
{[\%]}\end{array}$ & $\begin{array}{c}\mathrm{ph} \\
{[\mathrm{deg}]}\end{array}$ & $\begin{array}{l}\mathrm{mag} \\
{[\%]}\end{array}$ & $\begin{array}{c}\mathrm{ph} \\
{[\mathrm{deg}]}\end{array}$ & $\begin{array}{l}\mathrm{mag} \\
{[\%]}\end{array}$ & $\begin{array}{c}\mathrm{ph} \\
{[\mathrm{deg}]}\end{array}$ \\
\hline 1 & 100 & 0 & 100 & 0 & 100 & 0 & 100 & 0 \\
\hline 5 & 20 & 0 & 19.1 & 0 & 20 & 0 & 23.52 & 111 \\
\hline 7 & 14.3 & 0 & 13.1 & 0 & 14.3 & 0 & 6.08 & 109 \\
\hline 11 & 9.1 & 0 & 7.2 & 0 & 9.1 & 0 & 4.57 & -158 \\
\hline 13 & 7.7 & 0 & 5.6 & 0 & 0 & 0 & 4.2 & -178 \\
\hline 17 & 5.9 & 0 & 3.3 & 0 & 0 & 0 & 1.8 & -94 \\
\hline 19 & 5.3 & 0 & 2.4 & 0 & 0 & 0 & 1.37 & -92 \\
\hline 23 & 4.3 & 0 & 1.2 & 0 & 0 & 0 & 0.75 & -70 \\
\hline 25 & 4 & 0 & 0.8 & 0 & 0 & 0 & 0.56 & -70 \\
\hline 29 & 3.4 & 0 & 0.2 & 0 & 0 & 0 & 0.49 & -20 \\
\hline 31 & 3.2 & 0 & 0.2 & 0 & 0 & 0 & 0.54 & 7 \\
\hline 35 & 2.8 & 0 & 0.4 & 0 & 0 & 0 & 0 & 0 \\
\hline 37 & 2.7 & 0 & 0.5 & 0 & 0 & 0 & 0 & 0 \\
\hline
\end{tabular}

the fitness function, hence, the probability of capturing a global solution is higher than the previously proposed GA method [15];

- the dependency of the GA-FL solution on the initial conditions is weak and can escape local optima and converge to the near global solution. This is not true for other proposed algorithms (e.g., MSS, LV, MSS-LV, and fuzzy);

- compared with GA [15], the proposed method utilizes a wider search space and avoids numerical problems by computing fitness functions based on fuzzy approximate reasoning;

- the inclusion of PQ constraints in the proposed fuzzy fitness functions prevents the occurrence of harmonic parallel resonance. As a result, harmonic resonances are shifted to other nondisturbing frequencies by relocating and resizing capacitor banks;

- simulation results for the 18-bus and 123-bus IEEE distorted networks are presented. Compared with previous methods, the proposed GA-FL approach generates better results (e.g., greater annual benefits within the permissible region of constraints).

\section{APPENDIX}

Fig. 11 illustrates the 123-bus system [26], [27] simulated in Section VI, and Table VI shows the harmonic spectra of nonlinear loads that are included to inject harmonics. 


\section{REFERENCES}

[1] H. N. Ng, M. M. A. Salama, and A. Y. Chikhani, "Classification of capacitor allocation techniques," IEEE Trans. Power Del., vol. 15, no. 1, pp. 387-392, Jan. 2000.

[2] B. A. de Souza, H. N. Alves, and H. A. Ferreira, "Microgenetic algorithms and fuzzy logic applied to the optimal placement of capacitor banks in distribution networks," IEEE Trans. Power Syst., vol. 19, no. 2, pp. 942-947, May 2004.

[3] S. J. Huang, "An immune-based optimization method to capacitor placement in a radial distribution system," IEEE Trans. Power Del., vol. 15, no. 2, pp. 744-749, Apr. 2000.

[4] M. Delfanti, G. P. Granelli, P. Marannino, and M. Montagna, "Optimal capacitor placement using deterministic and genetic algorithms," IEEE Trans. Power Syst., vol. 15, no. 3, pp. 1041-1046, Aug. 2000.

[5] Y. Baghzouz, "Effects of nonlinear loads on optimal capacitor placement in radial feeders," IEEE Trans. Power Del., vol. 6, no. 1, pp. 245-251, Jan. 1991.

[6] Y. Baghzouz and S. Ertem, "Shunt capacitor sizing for radial distribution feeders with distorted substation voltage," IEEE Trans. Power Del., vol. 5, no. 2, pp. 650-657, Apr. 1990.

[7] B. Gou and A. Abur, "Optimal capacitor placement for improving power quality," in Proc. IEEE Power Eng. Meeting, Jul. 1999, vol. 1, pp. 488-492.

[8] G. Carpinelli, P. Varilone, V. D. Vito, and A. Abur, "Capacitor placement in three-phase distribution systems with nonlinear and unbalanced loads," Proc. Inst. Elect. Eng., Gen. Transm. Distrib, vol. 152, no. 1, pp. 47-51, 2005.

[9] C. T. Hsu, Y. H. Yan, C. S. Chen, and S. L. Her, "Optimal reactive power planning for distribution systems with nonlinear loads," in Proc. IEEE Region 10 Int. Conf. Computer, Communication, Control and Power Engineering, 1993, pp. 330-333.

[10] Z. Q. Wu and K. L. Lo, "Optimal choice of fixed and switched capacitors in radial distributions with distorted substation voltage," Proc. Inst. Elect. Eng., Gen. Transm. Distrib., vol. 142, no. 1, pp. 24-28, Jan. 1995.

[11] M. A. S. Masoum, M. Ladjevardi, E. F. Fuchs, and W. M. Grady, "Optimal sizing and placement of fixed and switched capacitor banks under non-sinusoidal operating conditions," in Proc. IEEE Summer Power Meeting, Jul. 2002, pp. 807-813.

[12] M. A. S. Masoum, M. Ladjevardi, E. F. Fuchs, and W. M. Grady, "Application of local variations and maximum sensitivities selections for optimal placement of shunt capacitor banks under non-sinusoidal operating conditions," in Proc. 34th Annu. North American Power Symp., pp. 507-515, NAPS-2002.

[13] H. C. Chin, "Optimal shunt capacitor allocation by Fuzzy dynamic programming," Elect. Power Syst. Res., vol. 35, pp. 133-139, 1995.

[14] M. A. S. Masoum, A. Jafarian, M. Ladjevardi, E. F. Fuchs, and W. M. Grady, "Fuzzy approach for optimal placement and sizing of capacitor banks in the presence of harmonics," IEEE Trans. Power Del., vol. 19, no. 2, pp. 822-829, Apr. 2004.

[15] M. A. S Masoum, M. Ladjevardi, A. Jafarian, and E. F. Fuchs, "Optimal placement, replacement and sizing of capacitor banks in distorted distribution networks by genetic algorithms," IEEE Trans. Power Del., vol. 19, no. 4, pp. 1794-1801, Oct. 2004.
[16] C. T. Su, G. R. Lii, and C. C. Tsai, "Optimal capacitor allocation using Fuzzy reasoning and genetic algorithms for distribution systems," Math. Comput. Model, vol. 33, pp. 745-757, 2001.

[17] F. Herrera and M. Lozano, "Adaptive genetic operators based on coevolution with Fuzzy behaviors," IEEE Trans. Evol. Comput., vol. 5, no. 2, pp. 149-165, Apr. 2001.

[18] D. E. Goldberg, Genetic Algorithms in Search, Optimization, and Machine Learning. Reading, MA: Addison-Wesley, 1989.

[19] J. D. Schaffer, J. D. Caruana, L. J. Eshelman, and R. Das, "A study of control parameters affecting online performance of genetic algorithms for function optimization," in Proc. 3rd Int. Conf. Genetic Algorithms, 1989, pp. 51-60.

[20] L. Davis, Handbook of Genetic Algorithms. New York: Van Nostrand Reinhold, 1991.

[21] D. Xia and G. T. Heydt, "Harmonic power flow studies, parts I and II," IEEE Trans. Power App. Syst., vol. PAS-101, no. 6, pp. 1257-1270, Jun. 1982.

[22] M. A. S. Masoum and E. F. Fuchs, "Transformer magnetizing current and iron core losses in harmonic power flow," IEEE Trans. Power Del., vol. 9, no. 1, pp. 10-20, Jan. 1994.

[23] IEEE Recommended Practices and Requirements for Harmonic Control in Electric Power Systems, IEEE Std. 519-1992, 1993.

[24] R. Kruse, J. Gebhardt, and F. Klawonn, Foundation of Fuzzy Systems. New York: Wiley, 1994.

[25] W. M. Grady, M. J. Samotyj, and A. H. Noyola, "The application of network objective functions for actively minimizing the impact of voltage harmonics in power systems," IEEE Trans. Power Del., vol. 7, no. 3, pp. 1379-1386, Jul. 1992.

[26] W. H. Kersting, "Radial distribution test feeders," in Proc. IEEE Power Eng. Soc. Winter Meeting, 2001, vol. 2, pp. 908-912.

[27] E. F. Fuchs and M. A. S. Masoum, Power Quality in Electrical Machines and Power Systems. New York: Academic, 2008.

Marjan Ladjavardi (S'05) received the B.S. and M.S. degrees in electrical engineering from the Iran University of Science and Technology, Tehran, Iran, in 1999 and 2001, respectively, and is currently pursuing the Ph.D. degree in electrical and computer engineering at the Curtin University of Technology, Perth, Australia.

Mohammad A. S. Masoum (SM'05) received the B.S., M.S., and Ph.D. degrees in electrical and computer engineering from the University of Colorado, Boulder, in 1983, 1985, and 1991, respectively,

$\mathrm{He}$ has published many papers in his area of expertise. His research interests include optimization, power quality and stability of power systems/electric machines, and distributed generation. Currently, he is an Associate Professor in the Electrical and Computer Engineering Department, Curtin University of Technology, Perth, Australia. 